\title{
Morphometric and Stereological Studies of the Pons and Medulla Oblongata of the African Striped Ground Squirrel (Xerus erythropus)
}

\section{Sheriff Olawale Ajeigbe *, Tauheed Abubakar Muazu, James Oliver Nzalak, Sunday Abraham Musa \& Ibrahim Abdullahi Iliya.}

* Department of Veterinary Anatomy, Ahmadu Bello University Zaria, Kaduna State, Nigeria. Department of Human Anatomy, Ahmadu Bello University Zaria, Kaduna State, Nigeria.

\section{With 2 figures, 8 tables. $\quad$ Received April, accepted for publication September 2021}

\section{Abstract}

The study was undertaken to investigate the structure and functional relationships of the pons and Medulla Oblongata of African Striped Ground Squirrel (Xerus erythropus). Twenty (20) adult African striped ground squirrels were used for this study (10 males and 10 females). The ground squirrels were obtained from the surrounding villages of Zaria Local Government, Kaduna state Nigeria. Each Squirrel was euthanized using ketamine hydrochloride at $80 \mathrm{mg} / \mathrm{kg}$ bw followed by gentle perfusion with neutral formal saline. A pair of scissors, chisel and scalpel blade were used to gently extract the brain (craniotomy). The extracted brain was fixed in Bouin's fluid for 24 hours and processed histologically. Morphometrically, the absolute brain weight was higher in male than female

while the brain length was higher in female. The absolute weight of medulla oblongata was significantly higher in male than female $(p<0.05)$. Stereologically, the neuronal volume of medulla oblongata was higher in female squirrel than in male while male squirrel has higher neuronal number of pons and medulla oblongata. In conclusion, the higher brain morphometry in male squirrels may be suggestive of a higher locomotive activity and a good climbing ability than the female counterpart.

Keywords: African stripped ground squirrel, Medulla Oblongata, Pons.

\section{Introduction}

Squirrels are mammals which belong to order rodentia. They are member of the family sciuridae and subfamily $\mathrm{Xe}$ rinae, genus Xerus (African ground 
squirrel), species Xerus erythropus consisting of small or medium size rodents (Thorington and Hoffmann, 2005). They are indigenous to America, Africa and Eurasia (Whatton, 2012).

Ground squirrel has an overall uniform appearance and their fur color varies with ages and season. Striped ground squirrels are diurnal herbivores, active during the day and spend almost their entire lives on the ground, although they are capable of climbing into bushes to reach their food. The juvenile has soft grayish tan fur while adults have buffy grey to sandy brown fur and light tan or buff around the head and underside. Their ears are small and closely appressed to the head; eyes are black, large and place high on the head enabling the animal to detect approaching danger from almost any direction. Their tail has hairs much longer than those on the body, which fan out to the sides, and are multi-coloured along their length, presenting a grizzled appearance (Wilson and Reeder, 2005). They have versatile claws for grasping, climbing and digging. Their weight varies during annual cycle but typical weight of adult is 0.5 to $1 \mathrm{~kg}$ (Thorington and Hoffmann, 2005). The squirrels live in open woodlands, grassy area like cemeteries, pastures, parks, or rocky country.

In Nigeria (especially south Nigeria), squirrel is one of the most commonly consumed small mammal species (bush meat) by rural dwellers as supplementary protein diet (Adeola and Decker, 1987; Ajayi, 1979). They are also used by Nigerian farmers in cultural ceremonies, for medicinal purposes (i.e. components of anti-poison drug and as ingredients in prevention of convulsion in children and also used to enhanced fertility in men) (Ajayi, 1979; Adeola, 1992).

The pons is a broad, horseshoe shaped portion of the brain consisting of large bundles of nerve fibers. The pons connects the two halves of the cerebellum and can be broadly divided into two parts; the basilar part, located ventrally and the pontine tegmentum, located dorsally (Henry et al., 2002). A number of cranial nerve nuclei are present in the pons which include pontine and motor nucleus of the trigeminal nerve ( $\mathrm{CN} \mathrm{V}$ ), located in the mid-pons

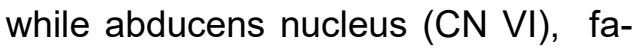
cial nerve nucleus (VII) and vestibulocochlear nuclei (vestibular nuclei and cochlear nuclei) (VIII) are located at lower end in the pons (Alexander, 1983). The pons also contains nuclei that relay signals from the forebrain to the cerebellum, along with nuclei that deal primarily with sleep, respiration, bladder control and posture (Saladin, 2007). The medulla oblongata is the conical part of the brain that extends from the pons to the medulla spinalis (Al-Shehri, 2007). It is broad above where it joins the level of the foramen magnum (Inderbir, 2003). Medulla 
oblongata is divided into two parts: an opened part (closed to the pons) and a closed part (closed to the spinal cord), the most rostral part of the medulla oblongata is the corpus trapezoideum (Al-Shehri, 2007).

Although, several studies have been conducted on the Pons and Medulla oblongata of other rodents but little or no research has been carried out on the pons and medulla oblongata of squirrels, thus this study will provide baseline data for detailed neuroanatomical descriptions of the pons and medulla oblongata of ground squirrels. This will in turn provide further laboratory research opportunities using ground squirrels as models and also provide additional information required for successful breeding as ground squirrels are good source of protein for domestic farmers in Nigeria.

\section{Material and Methods}

\section{Experimental animals and manage-} ment

Twenty (20) African striped ground squirrel ( 10 male and 10 female) were used for this study. The animals were captured live from the wild in Zaria and its environs. They were acclimatized for one month in standard laboratory cages in the animal pen of the Department of Veterinary Anatomy, Ahmadu Bello University, Zaria, Nigeria. The animals were given access to food and water ad libitum throughout the experimental period. They were physically examined during the pre-experimental period and only apparently healthy ones were utilized.

\section{Morphometric parameters}

The body weights of each squirrel were obtained using a weighing balance model JJ1000, USA with a capacity of $1000 \mathrm{~g}$ and sensitivity of $0.01 \mathrm{~g}$. The mean length, width and depth of the pons and medulla oblongata were obtained with a vernier caliper (MG6001DC, General Tools and Instruments Company, New York; sensitivity: $0.01 \mathrm{~mm}$ ). Gross pictures were taken using canon digital camera power shot (SX170 IS) with 64-megapixel sensor (focal length: $28-448 \mathrm{~mm}$, $7.5 \mathrm{~cm}$ (3.0") TFT. Histological pictures were taken using light microscope (Amscope, T120B) and a digital microscope camera (DCM 510-megapixel, Scope Photo $^{\circledR}$ China) at X40, X100, X250, X400.

\section{Brain extraction}

Each squirrel was euthanized using ketamine anaesthetic at $(80 \mathrm{mg} / \mathrm{kg} \mathrm{bw})$ David G. P. and Kangmei C. (1996). Each brain was perfused (intra-cardiac route) with $10 \%$ phosphate buffered formalin. Each skull was exposed after skinning and stripping off all the facial muscles within 30 minutes of euthanasia. Craniotomy was carried out through the calvaria to expose the dura matter, which was later cut with a curved pointed scissors. The falx 
cerebri and tentorium cerebelli were pulled from the longitudinal and transverse fissures by gentle traction. The cerebral vein was transected and at this stage, the brain was still in the cranium fixed in $10 \%$ phosphate buffered formalin for two days to enhance easy extraction as described by Ramaswamy (1978).

\section{Harvest of Pons and Medulla oblon- gata}

The pons and medulla oblongata were isolated from the rest of the brain by gently pulling apart the two cerebral hemispheres at the occipital lobe to expose the corpus callosum. The entire corpus callosum together with septum pellucidum and the body and rostral commissure of the fornix were severed in the midline and this separates the cerebrum from the brainstem and cerebellum. Then the flocculli of the cerebellum were raised manually to expose the cerebellar peduncle which was severed starting with the laterally located brachium restiformis, followed by the middle brachium pontis and then the brachium conjuctivum. The brainstem was free from the cranial nerves by simple trimming using scalpel blade, an incision was made at the transverse fissure between the pons and caudal colliculi to isolate the pons and medulla oblongata from the midbrain while incision made at the pontomedullary junction separates the medulla oblongata from the pons.

\section{Histology}

The extracted pons and medulla oblongata were fixed in Bouin's fluid for 24hour, dehydrated through series of ascending concentrations of ethanol (70\%, 90\%, 100\%, 100\%, 100\%) for 2 hours at each concentration, cleared in xylene, embedded in paraffin wax and sectioned at $5 \mu \mathrm{m}$. Hematoxylin \& Eosin was used for general histological evaluation (Kiernan, 2007) while, Cresyl fast violet stain was used for Nissl substance and nerve nuclei evaluation (Drury, 1967).

\section{Stereology}

Isotropic uniform random (IUR) samples were obtained by the orientator method (Ali, et al., 2012), Fig (1).

At first the pons and medulla oblongata each was placed at the center of the circle with equal divisions, and a random number (2) was calculated and selected from the random number table and the sample was cut here. Secondly, each part of the cut sample was again placed on a second circle with unequal divisions and another random number (6) was selected and the samples were cut here and then a trochar was used for getting the isotropic sections; then these sections were measured before and after processing with a digital vernier caliper (MG6001DC, General Tools and Instruments Company, New York; sensitivity: $0.01 \mathrm{~mm}$ ). They were fixed in Bouin's fluid for 24 hours; and thereafter dehydrated in a series of ascending 
concentration of alcohol, cleared in xylene, infiltrated with molten paraffin wax as described by Kiernan (2007). Degree of shrinkage were estimated by subtracting the final volume after processing from the initial volume before processing and then divided by the initial volume before processing $\left(\mathrm{S}_{1}-\mathrm{S}_{2} / \mathrm{S}_{1}\right)$ Braendgaard, et al. (1990).

\section{Serial Sectioning}

Serial Sections were cut with a rotatory microtome (LEICA) at $8 \mu \mathrm{m}$. A random number 3 was selected from the random number table and sections were randomly picked and floated out in a hot water bath, mounted on glass slides, left to air dry and stained with hematoxylin and eosin.

\section{Volume estimation}

A test point counting grid (Cavalieri estimator) was superimposed on the pons and medulla oblongata tissue sections and single test points hitting the pons and medulla oblongata were counted and summed (fig 2).

The volume changes of the pons and medulla oblongata were calculated as described by Gundersen et al. (1988) using the following computations:

$\mathbf{V}\left(\mathbf{m m}^{3}\right)=\overline{\mathrm{T}} \times \mathrm{a} / \mathrm{p} \times \sum \mathrm{P}_{\mathrm{i}}(\overline{\mathrm{T}}=$ distance from the $1^{\text {st }}$ section to the $13^{\text {th }}$ section; $a / p=$ area per point; $\sum P_{i}=$ sum of test points).

\section{Total neuronal number estimation}

These was done on pons and medulla oblongata of the African striped ground squirrel (xerus erythropus) using an unbiased counting frame called the Physical dissector.

Two unbiased counting frames were superimposed on systematically random

tissue sections (7 sections from each half of the medulla oblongata and pons). According to the dissector rules; the counting frame defines neuronal cells to be completely outside the frame if the cells touch the exclusion line as being outside the frame and not counted (black arrow); whereas neuronal cells that are completely within the frame or that touch the inclusion line were counted as being within the frame (white arrow) Fig 3. In addition, only distinct neuronal cells which are seen in the sampling section frame but are not seen in the reference section frame were counted and summed as $Q$. Each half, left or right is sample and reference section to each other (i.e. when counting the left as sample section, the right is reference section and vice versa). The total neuronal number was therefore estimated from the computations below as proposed by Schurmann et al. (1991).

\section{Data analysis}

All data obtained were expressed as mean \pm standard deviation $(n=20)$. Statistical comparison between pons and medulla Oblongata was made by subjecting the data to independent student t-test using GraphPad Prism 
version 5.0 for windows. Values of $\mathrm{P}<$ 0.05 was considered significant.

\section{Results}

\section{Morphometric results}

The mean body weight and body length of male ground squirrel was $504.41 \pm 38.52 \mathrm{gm}$ and $44.30 \pm 0.68$ $\mathrm{cm}$ while that of female squirrels was $458.78 \pm 18.60 \mathrm{gm}$ and $43.38 \pm 0.85$ $\mathrm{cm}$ respectively. The mean brain weight and length of male squirrel was $6.52 \pm 0.54 \mathrm{gm}$ and $32.76 \pm 1.85 \mathrm{~mm}$ while, $6.39 \pm 0.32 \mathrm{gm}$ and $37.54 \pm 2.49$ $\mathrm{mm}$ was obtained for female squirrels respectively. The mean brain volume of male squirrels was $6.18 \pm 0.56 \mathrm{ml}$ while that of female squirrel was 6.10 $\pm 0.33 \mathrm{ml}$ (Table 3).

The mean weight, length and volume of the medulla oblongata of male squirrel was $0.52 \pm 0.02 \mathrm{gm}, 13.41 \pm 1.10$ $\mathrm{mm}$ and $0.32 \pm 0.02 \mathrm{~cm}^{3}$ respectively, while, that of female counter part was $0.41 \pm 0.03 \mathrm{gm}, 2.57 \pm 1.23 \mathrm{ml}$ and 0.34 $\pm 0.02 \mathrm{~cm}^{3}$ respectively. The mean weight, length and volume of the pons of male squirrel was $0.16 \pm 0.02 \mathrm{gm}$, $6.37 \pm 0.83 \mathrm{ml}$ and $0.24 \pm 0.02 \mathrm{~cm}^{3}$ respectively, while that of female squirrels was $0.18 \pm 0.01 \mathrm{gm}, 4.92 \pm 0.56 \mathrm{ml}$ and $0.20 \pm 0.00 \mathrm{~cm}^{3}$ respectively (Table 4).

The brain of male squirrels constituted about $1.29 \%$ of their body weight while that of female squirrels constituted about $1.39 \%$ of their body weight. The brain length constituted about $73.95 \%$ of the body length in male and $86.54 \%$ of body length in females. The pons and medulla oblongata weight constituted about $2.45 \%$ and $7.98 \%$ of the brain weight in male squirrels while $2.82 \%$ and $6.42 \%$ in female squirrels respectively. The pons and medulla oblongata length constituted about $19.44 \%$ and $40.93 \%$ of the brain length in male and $13.11 \%$ and $33.48 \%$ in female squirrels respectively (Tables 3 and 4).

\section{Stereological results}

The result showed that the volume estimated for the left and right pons and medulla oblongata were $14610 \mathrm{~mm}^{3}$ and $9000 \mathrm{~mm}^{3}, 24285 \mathrm{~mm}^{3}$ and 21435 $\mathrm{mm}^{3}$ for male and $13350 \mathrm{~mm}^{3}$ and $12795 \mathrm{~mm}^{3}, 27315 \mathrm{~mm}^{3}$ and 27270 $\mathrm{mm}^{3}$ for female respectively (Tables 5 and 6). The total neuronal estimates for the male and female pons and medulla oblongata respectively were14.00338 $\times 10^{4}$ and 21.57704 $\times 10^{4}$, for male $10.00446 \times 10^{4}$ and $14.27286 \times 10^{4}$ for female (Tables 7 and 8). However, data obtained for the volume of medulla oblongata showed that the female squirrel had higher volume than the male squirrel (Table 6) but the neuronal number in the pons and medulla oblongata of the male squirrel was higher than the female counterpart (Tables 7 and 8).

\section{Discussion}

The pons and medulla oblongata are the caudal extend of the brainstem. The pons is convex and smooth ventrally and triangular dorsally while the 
medulla oblongata opens rostrally and closed caudally. The mean body weight of squirrels (male: $0.18 \pm$ $0.01 \mathrm{gm}$; female: $458.78 \pm 18.60 \mathrm{gm}$ ) and percentage brain weight (male: $1.29 \%$; female: $1.39 \%$ ) was relatively higher than that reported in African giant rat by Nzalak et al., (2005) and in grasscutter by Ajayi et al., (2010). The ratio of brain weight to body weight $(1: 75)$ was higher than that reported in grasscutter (1:214) by Ajayi et al., (2010), in rabbit (1:300) by Russel, (1979) and in African giant rat (1:193) by Nzalak, et al., (2005). The body weight of male $(504.41 \pm 38.52 \mathrm{~g})$ and female $(458.78 \pm 18.60 \mathrm{~g})$ squirrels obtained in this study are statistically insignificance $(p>0.05)$, this is similar to the findings of Nowak and Walker, (1999) who reported that the mean body weight of male and female African giant rats is statistically insignificance, this is equally in line with the findings of Becker and Middleton (1979) who reported that male and female African white-tailed rats show insignificant variation in body weight. Male squirrels were observed to have higher body weight than females, this agrees with the findings of Oto and Haziroglu, (2009), who reported that male rodents have higher body weight than females, but this is in contrary to the findings of Byanet, (2009) who reported that female grasscutters have higher body weight than male.

Male squirrels have larger brain size than female counterparts in this study, which suggests that male squirrels navigate better in their habitats than females, this is in line with the findings of Byanet and Dzenda, (2014) who reported that large brain size is required to navigate structurally complicated habitats within species but not across species of rodents. Similarly, Hart, et al. (2001) and Mace, et al. (1981), reported that larger animal usually has larger brain than smaller animal and that rodents brain size is related to factors like complex habitat, specialized diet, nocturnal behavior, climbing and burrowing ability.

The weight of medulla oblongata (male: $0.52 \pm 0.02 \mathrm{gm}$; female: 0.41 $\pm 0.03 \mathrm{gm}$ ) and pons (male: $0.16 \pm 0.02$ $\mathrm{gm}$; female: $0.18 \pm 0.01 \mathrm{gm}$ ) obtained in this study is lower than that reported in African giant rat by lbe, et al. (2010) and in grasscutter by Byanet and Dzenda (2014). The mean weight of the medulla oblongata of the male squirrel was statistically higher than that of the female squirrel $(p<0.05)$, this is in agreement with the findings of Ibe, et al. (2010) who reported a higher medulla oblongata weight in male African giant rat than females. These sexual dimorphism in brain weight may not mean that sex with heavier brain is more intelligent, however, Pilleri, et al. (1982/5) reported that the internal structural complexity of the brain and interconnection of specific brain center are the most important factors in the evolution of intelligence and not brain size. 
The pons and medulla oblongata of Male squirrels have higher neuronal number than their female counterparts which is suggestive of a better consciousness and alertness in male squirrels than females, this is in line with the neuronal estimate of the neocortex of brown rats by Korbo, et al. (1990), neocortex of domestic pigs by Jelsing et al. (2006), pons and medulla oblongata of African elephant by Suzana, et al. (2014).

\section{Conclusion}

The higher brain morphometry in male squirrels may be suggestive of a higher locomotive activity and a good climbing ability than the female counterpart. While, the higher neuronal number of pons and medulla oblongata in male squirrels confers them greater alertness and consciousness than female squirrels.

Conflict of interest: No conflict of interest

\section{Ethical Statement}

An ethical approval was given by Animal research committee of Ahmadu Bello University Zaria with an approval number of ABU/CAUC/2016/038.

Funding: The research was funded by the corresponding author

\section{Authors contributions}

All authors contributed substantially to the design, acquisition, and analysis of the study. Writing and revising for intellectual consumption was also collectively done.

\section{References}

Adeola, M.O. (1992): Importance of wild animals and their parts in the culture, religious festivals, and traditional medicine of Nigeria. Environ. Conser., 19:125-134.

Adeola, M.O., \& Decker, E. (1987): Wildlife utilization in rural Nigeria. In Clers, B. D. (edition) Proceedings of the International symposium and conference on wildlife management in Sub-Saharan Africa, Harare, Zimbabwe, pp 512-521

Ajayi, I. E., Ojo, S. A., Ayo, J. O., \& Ibe, C. S. (2010): Histomorphometric studies of the Urinary tubules of African grasscutter (Thryonomys swinderianus). JVA, 3(1): 17-23.

Byanet, O. Onyeanusi, B.I. \& Ibrahim, N.D.G. (2009). Sexual dimorphism with respect to the macro-morphometric investigations of the forebrain and cerebellum of the Grasscutter (Thyronomys swinderianus). Int. J. Morphol., 27 (2): 361-365.

Byanet, O., \& Dzenda, T. (2014): Quantitative Biometry of Body and Brain in the Grasscutter (Thryonomys swinderianus) and African Giant Rat (Cricetomys gambianus): Encepha- 
lization Quotient Implication. Research in Neurosci., 3(1): 1-6.

Byanet, O., \& Dzenda,T. (2012): Quantitative Biometry of Body and Brain in the Grasscutter (Thryonomys Swinderianus) and African Giant Rat (Cricetomy Gambianus). Res. in Neurosci., Pp. 2326-1226.

David, G. P., \& Kangmei, C. (1996): NMDA receptor-blocker ketamine protects during acute carbon monoxide poisoning, while calcium channelblocker verapamil does not. J. appl. toxicology, 16 (4): 297-304.

Drury, R. A. B. (1967): Carlton's histological technique. Ann. Inter. Med., 67:233,

Gundersen, I.U.G., Bagger, P., \& Bendtsen, T.F. (1988): The new stereological tools: disectors, fractionator, nucleator and point sampled intercepts and their used in. Path. Res. Diag., APMIS, 96:875-881.

Hart, B.L., McCoy, M., \& Sarath, C.R. (2001): Cognitive behavior in Asian elephant: Use and modification of branches for fly switching. Ani. Behaviour, 62(5):839-847.

Henry D. P, Starman, B. J., Johnson, D. G., \& Williams, R. H. (2002): A sensitive radioenzymatic assay for noepinephrine in tissues and plasma. Life Sci., 16 (3): 375-384.

Ibe, C.S. (2010): Anatomic study of the mesencephalic tectum and myelencephalon in the African giant (cricetomys gambianus, water house1840). Vet. Res., Pp.97-99

Inderbir, S. (2003): Essentials of Anatomy, Jaypee brothers' medical publishers (p) limited. New delhi, 6:219-224.

Jelsing, J., Rune, N., Aage, K.O., Nanna, G., Ralf, H. and Pakkenberg, B. (2006): The postnatal development of neocortical neurons and glial cells in the Gottingen minipig and domestic pig brain. J. Experimental Bio., 209: 1454-1462.

Kiernan, J.A. (2007): Histochemistry of staining methods for normal and degenerating myelin in the central and peripheral nervous systems. J. Histotech., 30(2):87-1

Korbo, L., Pakkenberg, Bente., Ladefoged, O., Gundersen, H. G., Arlien-Soborg, P., \& Pakkenberg, H. (1990): An efficient method for estimating the total number of neurons in rat brain cortex. J. Neurosci. Methods, 31(2): 93-100.

Mace, G.M., Harvey, P.H., \& Clutton, B. (1981): Brain size and ecology in small mammals. J. Zool., London. 333345.

Nowak, R. M. \& Walker, E. P. (1999). Walkers mammals of the world. JHU press, Vol. 1, $6^{\text {th }}$ ed.

Nzalak, J. O., Wanmi, N., \&Samuel, M. O. (2015): Morphometric Study on 
the Digestive system of the Wild Gray Squirrel (sciurus carolinensis). JVA, 8(2):59-68.

Oto, C. \& Haziroglu, R. M. (2009). Macro-anatomical investigation of encephalon in donkey. Ankara Uni. Vet. Fak. Derg., 56: 159-164.

Pilleri, G., Gihr, M., \& Kraus, C. (1984): Cephalization in rodents with particular reference to the Canadian beaver (Castor canadensis). Institute of Brain Anatomy, University of Berne, Pp. 11-102.

Ramaswamy, S. (1978): Removal of the brain. A new procedure. Italian $\mathrm{J}$. Anat. and Embryol., 82: 105-110.

Russel, M.S. (1979): The brain size and intelligence, In: Oakly and plotkin (Eds). Comparative perspective in Behavior and Evolution. Ass. book pub. London, Pp.127-153.

Saladin, K. S. (2007): Anatomy and physiology; the unity of form and function. Dubuque, IA: McGraw-Hill.
Schurmann, G., Mattfeldt, T., Feichter, G., Koretz, K., Moller, P. \& Buhr, H. (1991). Stereology, flow cytometry and immunohistochemistry of follicular neoplasm of the thyroid gland. Elsevier: Human Path., 22 (2): 179-184.

Suzana, H., Kamila, A., Kleber, W., Jairo, P., Debora, M., Larissa, M., \& Paul, M. (2014): The elephant brain in numbers. Front. Neuroanat., 8:46-50.

Thorington, R., \& Hoffmann, R. (2005): Family Sciuridae. Mammal species of the World. A taxonomic and geographic reference. JHU press, Baltimore, UK, Pp754-818

Whatton, F. (2012): Squirrel of the world. JHU press Baltimore, UK, Pp 8.

Wilson, D.E., \& Reeder, D.M. (2005): Mammal species of the world. A taxonomic and geographic reference $\left(3^{\text {rd }}\right.$ ed). JHU press Baltimore, UK, Pp 754819.
A

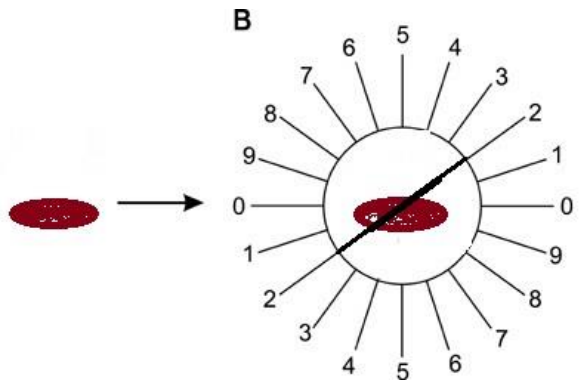

C

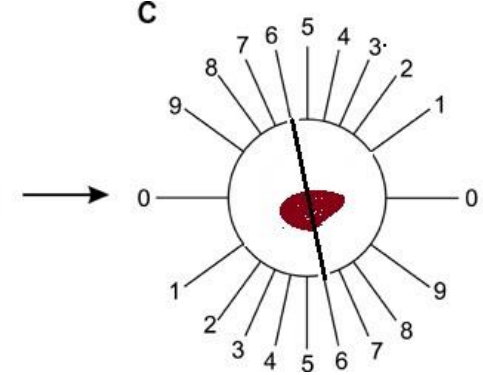

Fig (1): The Orientator 44 grid. 


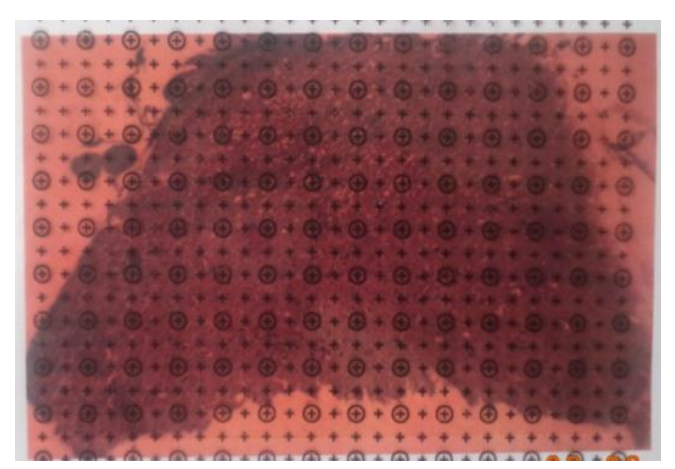

Fig (2): The Cavalieri estimator grid.
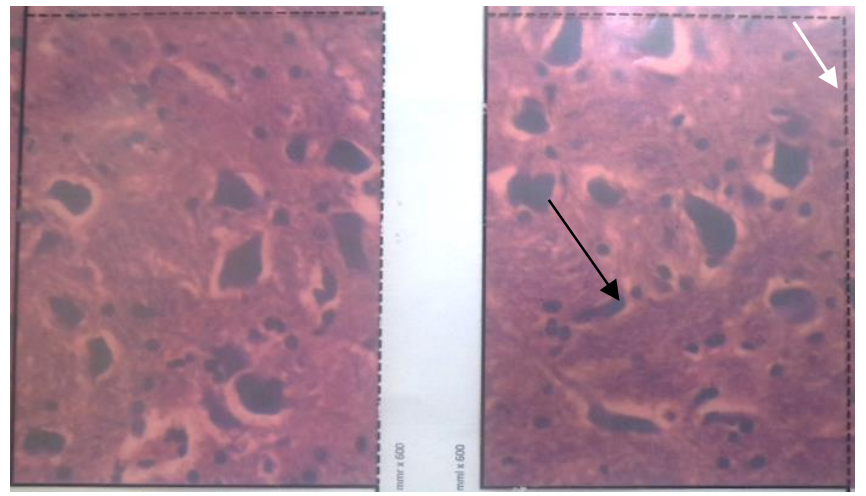

Fig (3): The physical dissector counting frames

Table (1): Volume estimation (Gundersen, et al., 1988), cavalieri estimator point counting method.

\begin{tabular}{lcccc}
\hline Sections & $\mathbf{P}_{\mathbf{1}}$ & $\mathbf{P}_{\mathbf{1}} \times \mathbf{P}_{\mathbf{1}}$ & $\mathbf{P}_{\mathbf{1}} \times \mathbf{P}_{1+1}$ & $\mathbf{P}_{\mathbf{1}} \times \mathbf{P}_{1+2}$ \\
\hline 1 & 283 & 80,089 & 100,748 & 52,921 \\
2 & 356 & 126,736 & 66,572 & 112,921 \\
3 & 187 & 34,969 & 59,279 & 53,482 \\
4 & 317 & 100,489 & 90,662 & - \\
5 & 286 & 81,796 & - & - \\
\hline$\sum \mathrm{P}_{1}=1,429 \sum \mathrm{P}_{1} \times \mathrm{P}_{1}=424,076(\mathrm{~A}) \sum \mathrm{P}_{1} \times \mathrm{P}_{1+1}=317,261(\mathrm{~B}) \sum \mathrm{P}_{1} \times \mathrm{P}_{1+2}=219,255(\mathrm{C})$
\end{tabular}

Noise due to errors in the sampling:

Noise $=0.0724 \times B / \sqrt{ } A \times \sqrt{ } \times \sum P_{1}\left(\sum P_{1}=\right.$ sum of test points $)$. 
Variations due to the systematic random sampling of the serial sections were calculated:

VARsurs $=3($ A-Noise $)-4(B+C)+C$

Total variance $($ TVAR $)=$ Noise + VARsurs

Coefficient of error due to the entire sampling process (CE) was calculated:

$\mathrm{CE}=\sqrt{ } \mathrm{TVAR} / \sum \mathrm{P}_{1}$.

Table 2: Estimating total neuronal number with the physical dissector

\begin{tabular}{|c|c|c|}
\hline Dissector & $Q^{-}$left & $Q^{-}$right \\
\hline 1 & 2 & 1 \\
\hline 2 & 4 & 3 \\
\hline 3 & 4 & 2 \\
\hline 4 & 8 & 8 \\
\hline 5 & 3 & 7 \\
\hline 6 & 10 & 9 \\
\hline 7 & $\Sigma Q^{-} \quad \begin{array}{r}8 \\
39\end{array}$ & $\begin{array}{r}3 \\
=33\end{array}$ \\
\hline
\end{tabular}

$\begin{array}{lcc}N=N_{v} \times V_{\text {ref }} & \text { Vref }=\sum Q^{-} / \mathrm{n} \times \text { vdis } & \text { Vdis }=\mathrm{t} \times \text { a(frame }) / \text { magnification }^{2}=21 \\ \times 110 \times 175 / 600 \times 600 & n=7+7 & \sum Q^{-}=39+33\end{array}$

Where $\mathrm{Nv}=$ numerical density, $\mathrm{V}(\mathrm{ref})=$ volume of the structure estimated with the cavalieri estimator, $\mathrm{V}($ dis $)=$ volume of all dissector probes placed in the structures, $\mathrm{a}(\mathrm{fra})=$ area of counting frame which is standardize from the grid as $110 \times 175$.

Noise due to errors in the sampling:

Noise $=0.0724 \times B / \sqrt{ } A \times \sqrt{ } n \times \sum Q_{1}$.

Variations due to the systematic random sampling of the serial sections was calculated:

VARsurs $=3$ (A-Noise) $-4(B+C)+C$

Total variance $($ TVAR $)=$ Noise + VARsuRs

Coefficient of error due to the entire sampling process (CE) was calculated:

CE $=\sqrt{ } T V A R / \sum Q_{1}$. 
Pons and Medulla Oblongata of the Squirrel.

Ajeigbe, et al.,

Table (3): Mean \pm SD values of body weight, length and brain parameters of African stripped ground squirrels (Xerus erythropus).

\begin{tabular}{|c|c|c|c|}
\hline \multirow[t]{2}{*}{ Parameters } & \multicolumn{2}{|c|}{ Mean士 SD $(n=20)$} & \multirow[t]{2}{*}{ p-value } \\
\hline & Male & Female & \\
\hline BW (gm) & $504.41 \pm 38.52$ & $458.78 \pm 18.60$ & 0.317 \\
\hline $\mathrm{BL}(\mathrm{cm})$ & $44.30 \pm 0.68$ & $43.38 \pm 0.85$ & 0.424 \\
\hline BRW (gm) & $6.52 \pm 0.54$ & $6.39 \pm 0.32$ & 0.845 \\
\hline $\mathrm{BRL}(\mathrm{mm})$ & $32.76 \pm 1.85$ & $37.54 \pm 2.49$ & 0.162 \\
\hline $\mathrm{BRV}(\mathrm{ml})$ & $6.18 \pm 0.56$ & $6.10 \pm 0.33$ & 0.906 \\
\hline$\%$ BRW & $1.29 \%$ & $1.39 \%$ & - \\
\hline$\%$ BRL & $73.95 \%$ & $86.54 \%$ & - \\
\hline
\end{tabular}

Key: $B W=$ Body weight, $B L=$ Body length, $B R W=$ Brain weight, $B R L=$ Brain length, $B R V=$ Brain volume, $\% B R W=$ Percentage brain weight and $\% B R L=$ Percentage brain length.

$\mathrm{P}<0.05$ are statistically significant 
Pons and Medulla Oblongata of the Squirrel.

Ajeigbe, et al.,

Table (4): Mean \pm SD values of the dimensions of Pons and medulla oblongata of African stripped ground squirrels (Xerus erythropus).

\begin{tabular}{|c|c|c|c|}
\hline \multirow[t]{2}{*}{ Parameters } & \multicolumn{2}{|c|}{ Mean \pm SD $(n=20)$} & \multirow[t]{2}{*}{ p-value } \\
\hline & Male & Female & \\
\hline MW (gm) & $0.52 \pm 0.02$ & $0.41 \pm 0.03$ & $0.026^{*}$ \\
\hline $\mathrm{ML}(\mathrm{mm})$ & $13.41 \pm 1.10$ & $12.57 \pm 1.23$ & 0.513 \\
\hline $\mathrm{MV}\left(\mathrm{cm}^{3}\right)$ & $0.32 \pm 0.02$ & $0.34 \pm 0.02$ & 0.545 \\
\hline PW (gm) & $0.16 \pm 0.02$ & $0.18 \pm 0.01$ & 0.484 \\
\hline \multirow[t]{2}{*}{ PL (mm) } & $6.37 \pm 0.83$ & $4.92 \pm 0.56$ & 0.189 \\
\hline & $0.24 \pm 0.02$ & & \\
\hline $\mathrm{PV}(\mathrm{cm} 3)$ & & $0.20 \pm 0.00$ & 0.178 \\
\hline$\% \mathrm{MW}$ & $7.98 \%$ & $6.42 \%$ & - \\
\hline$\% M L$ & $40.93 \%$ & $33.48 \%$ & - \\
\hline$\% \mathrm{PW}$ & $2.45 \%$ & $2.82 \%$ & - \\
\hline$\% \mathrm{PL}$ & $19.44 \%$ & $13.11 \%$ & - \\
\hline
\end{tabular}

Key: $\mathrm{MW}=$ Medulla weight, $\mathrm{ML}=$ Medula length, $\mathrm{MV}=$ Medulla volume, $\mathrm{PW}=\mathrm{Pons}$ weight, $\mathrm{PL}=$ Pons length, $\mathrm{PV}=$ Pons volume, $\% \mathrm{MW}=$ Percentage medulla weight, $\% \mathrm{ML}=$ Percentage medulla length, \% PW= Percentage pons weight, and \% PL= Percentage pons length.

$\mathrm{P}<0.05$ are statistically significant

Table (5): volume estimation of Pons of African striped ground squirrel

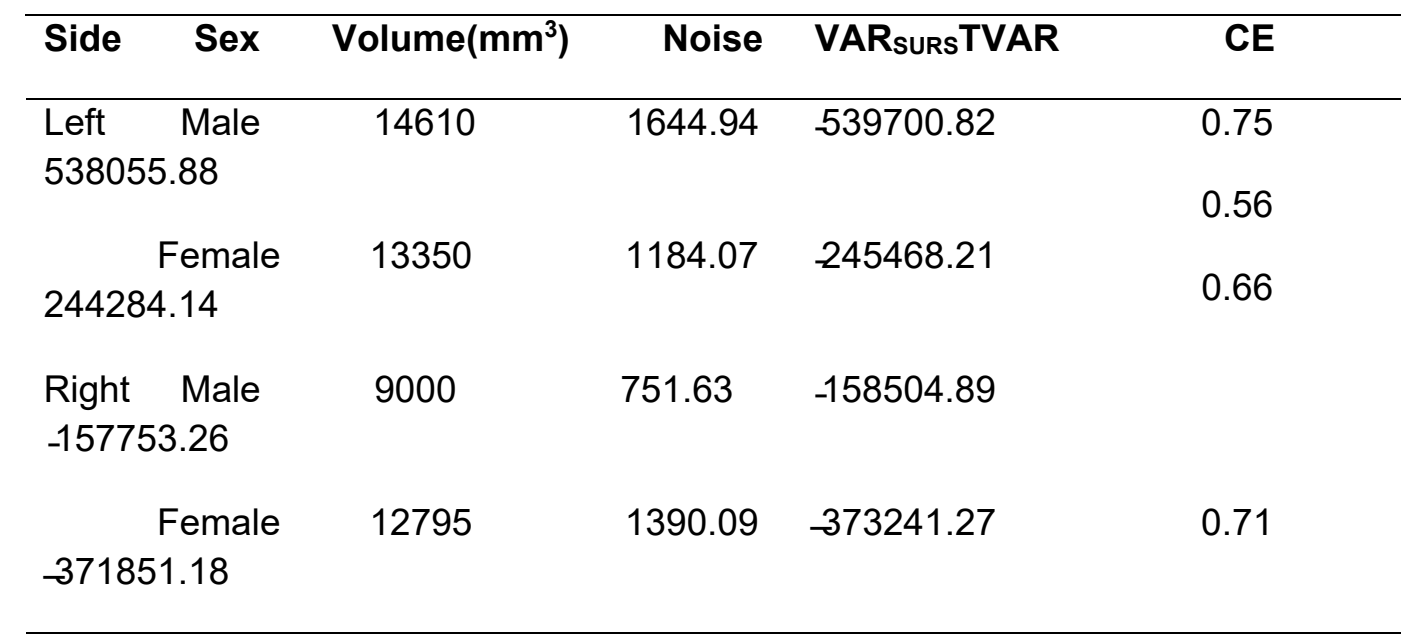


Pons and Medulla Oblongata of the Squirrel.

Ajeigbe, et al.,

Table (6): volume estimation of medulla oblongata of African striped ground squirrel

\begin{tabular}{clccccc}
\hline Sides & Sex & VOLUME $\left(\mathrm{mm}^{3}\right)$ & NOISE & VARsurs & TVAR & CE \\
\hline Left & male & 24285 & 3469.85 & -1472396.55 & -1468926.70 & 0.74 \\
& Female & 27315 & 4259.10 & -1782924.30 & -1778665.20 & 0.73 \\
\multirow{2}{*}{ Right } & Male & 21435 & 2981.17 & -1102034.51 & -1099053.34 & 0.73 \\
& Female & 27270 & 3993.99 & -1924995.97 & -1921001.98 & 0.76
\end{tabular}

Table (7): Estimated total neuronal number of pons of African striped ground squirrel

\begin{tabular}{llcccr}
\hline Sex & Tot.neuronal estimate & NOISE & VARsurs & TVAR & CE \\
\hline Male & $14.00338 \times 10^{4}$ & 20.87 & -1442.61 & -1421.74 & 0.80 \\
Female & $10.00446 \times 10^{4}$ & 10.86 & -577.58 & -566.72 & 0.74 \\
\hline
\end{tabular}

Table (8): Estimated total neuronal number of medulla oblongata of African striped ground squirrel

\begin{tabular}{lccccc}
\hline Sex & Tot.neuronal estimate & NOISE & VARsurs & TVAR & CE \\
\hline Male & $21.57704 \times 10^{4}$ & 13.75 & -762.25 & -748.5 & 0.70 \\
Female & $14.27286 \times 10^{4}$ & 3.59 & -140.77 & -137.18 & 0.55 \\
\hline
\end{tabular}

Author address:

Dr. Sheriff Olawale Ajeigbe

Sherifdvm@gmail.com 


\section{Animal species in this Issue}

\section{African Striped Ground Squirrel (Xerus erythropus)}

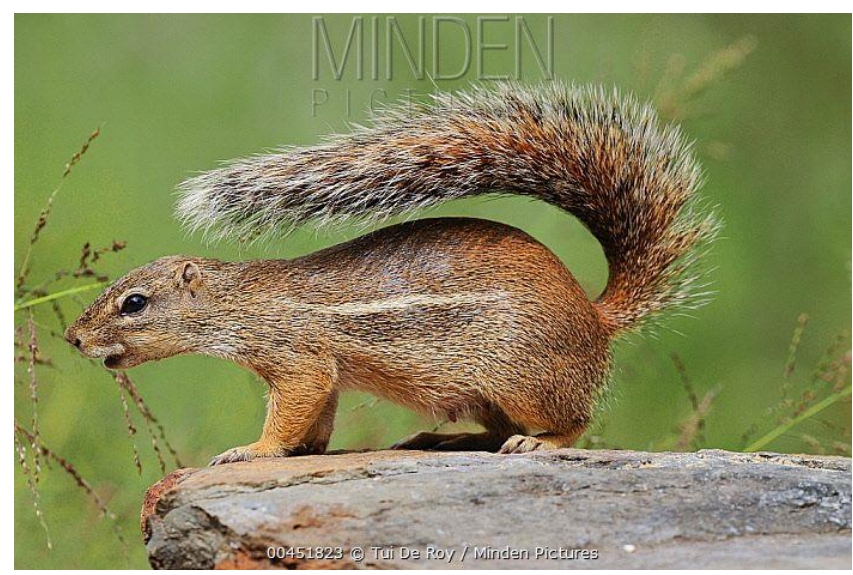

Kingdom: Animalia \& Phylum: Chordata \& Class: Mammalia \& Order: Rodentia \& Family: Sciuridae \& Genus: Xerus \& Species: $X$. erythropus

Striped ground squirrels are diurnal herbivores, and spend almost their entire lives on the ground, although are capable of climbing into bushes to reach food. They eat a range of seeds, nuts, and roots, and can be an agricultural pest, eating crops such as cassava, yams, cotton bolls, peanuts, and sweet potatoes. They may occasionally supplement their diet with eggs, insects, and other small animals. Their predators include servals, jackals, birds of prey, and common puff adders.

They forage throughout home ranges of about 12 hectares (30 acres) in semi-arid terrain, but their ranges overlap and they make frequent forays into surrounding areas in search of food. They mark their territories using scent glands on their cheeks, which they rub onto stones and tree trunks, although they do not appear to defend them from intruders.

The squirrels spend the night in burrows, which they dig with their large claws. Their burrows are usually simple in structure, with a central nest less than a meter below the surface, a single entrance tunnel, and a few blind-ending tunnels that almost reach the surface. The latter are used as escape routes, allowing the squirrel to rapidly break through to the surface; the main entrance tunnel is often also blocked with a temporary pile of dirt at night. Burrows may also contain caches of food, although these are more commonly located some distance away and concealed beneath stones or dead leaves. They also bury their urine, but not their dung.

Source: Wikipedia, the free encyclopaedia 